\title{
CBR of Soaked Clay Drained by Sandy Layer
}

\author{
Robert Nini \\ University of Balamand \\ Balamand, El-koura, Lebanon \\ robert.nini@balamand.edu.lb
}

\begin{abstract}
The quality of pavement is affected mostly by the type of subgrade soil, and in many countries, the subgrade soil is clay. The California Bearing Ratio CBR of clay is generally very low which leads to a thicker layer of pavement and sub base materials. This increase in quantities leads to a significant increase in cost. Since the use of the clay as subgrade is inevitable, many private and public institutions searched on a way to increase its CBR, but most of the conducted studies focused on increasing clay CBR by reinforcing the clay either by geogrids or by fibers which are very expensive. One common finding in all the studies was that the CBR of unsoaked clay is higher than CBR of soaked one which means that CBR of clay is affected by its moisture content. In our work, the objective is to increase the CBR of clay by draining it instead of reinforcing it. Drainage can be obtained by adding a layer of granular soil between clay layers. Sand was used as granular soil for the sake of its workability in the CBR mold and for its relatively small particles size. Our aim is to verify if sandy layer can play a drainage role for the clayey soil and to also find the most efficient position of the sandy layer. We collected six soils from different regions to cover as much as possible the different clay types in Lebanon. For each soil, we found CBR values for clay alone and clay with layer of sand and compares them. Identification tests were necessary in order to build our analysis. At the end, from the results and analysis, we found the position of the sandy layer which increases most the clay CBR and we proved that the existence of sandy layer is beneficial for CBR of clay.
\end{abstract}

Keywords: Clay, subgrade, CBR, sand, drainage.

\section{Introduction}

Clayey soils are known by their weak value of soaked California Bearing Ratio CBR. Even after placing borrowed subbase and base granular materials above the subgrade clayey soil, the clay will be subjected to settlement under traffic surcharge. Previous researches worked on clay CBR increasing by reinforcing it with geogrids [1] or with fibres [2]. Reinforcing materials are very expensive and working on the stiffness only does not solve the whole problem. The real problem of the clayey subgrade is the excess of pore water pressure trapped between clay particles. The most efficient solution is to dissipate the excess water pressure by using a drain material consisting of any granular soil. Due to the laboratory scale of our soil container which consists of cylindrical mould of 6 inches diameter, the selection of sand as granular soil will be the best choice regarding its small particles diameter. The objective of this project is to find the position of the sandy layer which will enhance most the CBR of clayey soils and to find how much it will increase CBR of clayey soil.

This research consists of two parts:

a. Experimental part: This section deals with tests performed in soil laboratory as Proctor test [3] and CBR test [4]. More identification experiments will be needed to recognize the clayey soils parameters as sieve analysis [5], specific gravity [6], Atterberg limits [7] and hydrometer test [8].

b. Analysis part: Based on the results of the experiments done on different clayey soils collected from different zones of Lebanon, the effect of the sandy layer on the CBR values of the clayey soils will be studied.

\section{Experimental Part}

Working on different types of clayey soils was a necessity in order to cover as much as possible different types of Lebanese clayey soils. Dealing with clay is not a simple task because of its sticky behaviour and its high sensitivity to water [9]. Many assumptions were made in order to accomplish all the experiments. Otherwise, the project could not progress. The steps and the assumptions were exactly the same for the six soils. 


\subsection{CBR and Proctor tests}

We collected six clayey samples from different regions of Lebanon. The six soils are extracted from Daher El Ain, Aitou, Koura, Amyoun, Ehden and Zgharta regions. First, the Proctor test was done separately on the six soils in order to find the optimum moisture content OMC which will be used to compact these soils for the CBR test. After it, the CBR test will be performed on the six clayey collected samples and will be named CBR of "Pure Clay" of each one. Then, we will repeat the CBR test on these clayey soils but this time after placing the sandy layer within the five compacted layers of soil in the mould. Each time, we will change the position of the sandy layer according to the followings:

Case 1: compacting the clayey soil in Proctor mould including a sandy layer at bottom and four layers of clay above the sandy layer. This case was named "Bottom sandy layer".

Case 2: compacting the clayey soil in Proctor mould including at bottom a clayey layer followed by a sandy layer and three other layers of clay after the sandy one. This case was named "Second sandy layer".

Case 3: compacting the clayey soil in Proctor mould including at bottom two clayey layers followed by a sandy layer and two other layers of clay above the sandy one This case was named "Third sandy layer".

Case 4: compacting the clayey soil in Proctor mould including at bottom three clayey layers followed by a sandy layer and other layer of clay above the sandy one. This case was named "Upper sandy layer".

Figure 1 shows one of the position of sandy layer in Proctor mould after compaction.

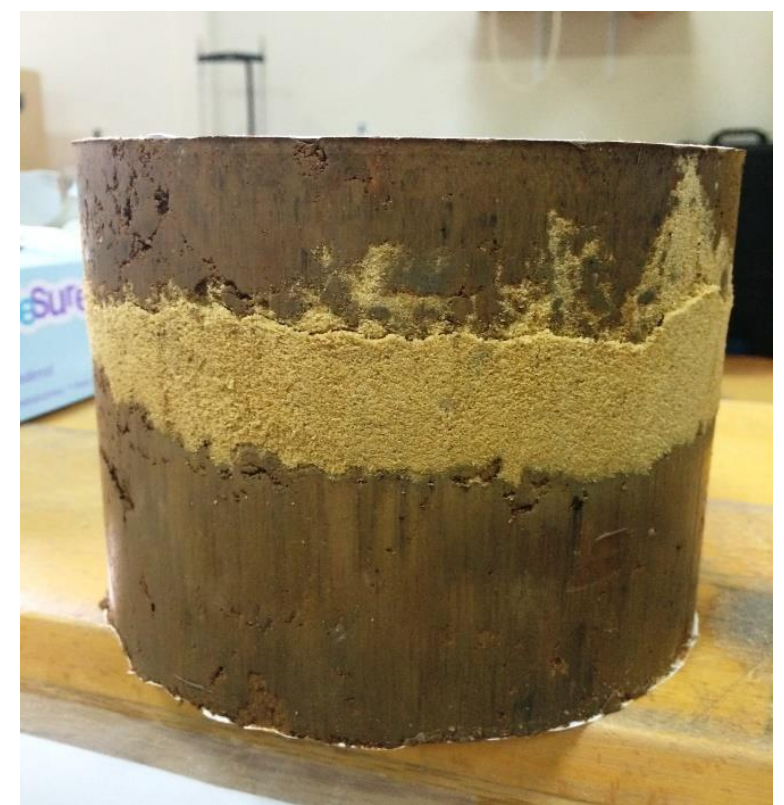

Fig. 1: One of the position of sandy layer in Proctor mould after compaction.

Once, after performing all the tests, comparison of the CBR values on all these cases will be done in order to find the optimum values.

\subsection{Identification tests}

In order to analyse the behaviour of each clayey sample and its five cases (one case of pure clay and four others cases with sandy layer at different positions), performing the identification tests is a must especially that some of the clayey parameters affect directly its CBR value [10].

As for the identification tests, we performed the following tests:

a- Sieve analysis to get the percentage of particles passing sieve number 200 ,

b- Atterberg limits in order to get the liquid limit, the plastic limit and the plasticity index.

c- Specific gravity test was a necessity in order to finish the hydrometer calculations

d- Hydrometer test is used to get the silty and clayey fractions. 
More than three hundred hours we have passed in the laboratory to finish all needed experiments which their results are presented in table 1.

Table 1. The clay fraction, the silt fraction, the plasticity index, the optimum moisture content OMC and the maximum dry density MDD of the six used clayey samples.

\begin{tabular}{|c|c|c|c|c|c|c|}
\hline & $\begin{array}{c}\text { Soil 1 } \\
\text { Daher El Ain }\end{array}$ & $\begin{array}{c}\text { Soil 2 } \\
\text { Aitou }\end{array}$ & $\begin{array}{c}\text { Soil 3 } \\
\text { Koura }\end{array}$ & $\begin{array}{c}\text { Soil 4 } \\
\text { Amyoun }\end{array}$ & $\begin{array}{c}\text { Soil 5 } \\
\text { Ehden }\end{array}$ & $\begin{array}{c}\text { Soil 6 } \\
\text { Zgharta }\end{array}$ \\
\hline Clay fraction \% & 58 & 39.5 & 51.4 & 41.9 & 42.4 & 50.2 \\
\hline Silt fraction \% & 19 & 19.5 & 19.6 & 21.1 & 37.6 & 24.8 \\
\hline $\begin{array}{c}\text { Plasticity Index } \\
\%\end{array}$ & 32.6 & 26.1 & 30.4 & 27.3 & 29.2 & 24.8 \\
\hline OMC \% & 19.2 & 17.4 & 18.8 & 18.0 & 13.0 & 14.2 \\
\hline MDD KN/m & 17.35 & 17.60 & 17.39 & 17.49 & 16.54 & 16.85 \\
\hline
\end{tabular}

\section{Analysis of Results}

After performing the CBR tests on the different clayey soils according to the five cases, we plotted all the CBR curves of each six soils according to the five cases in figure 1 to figure 6.

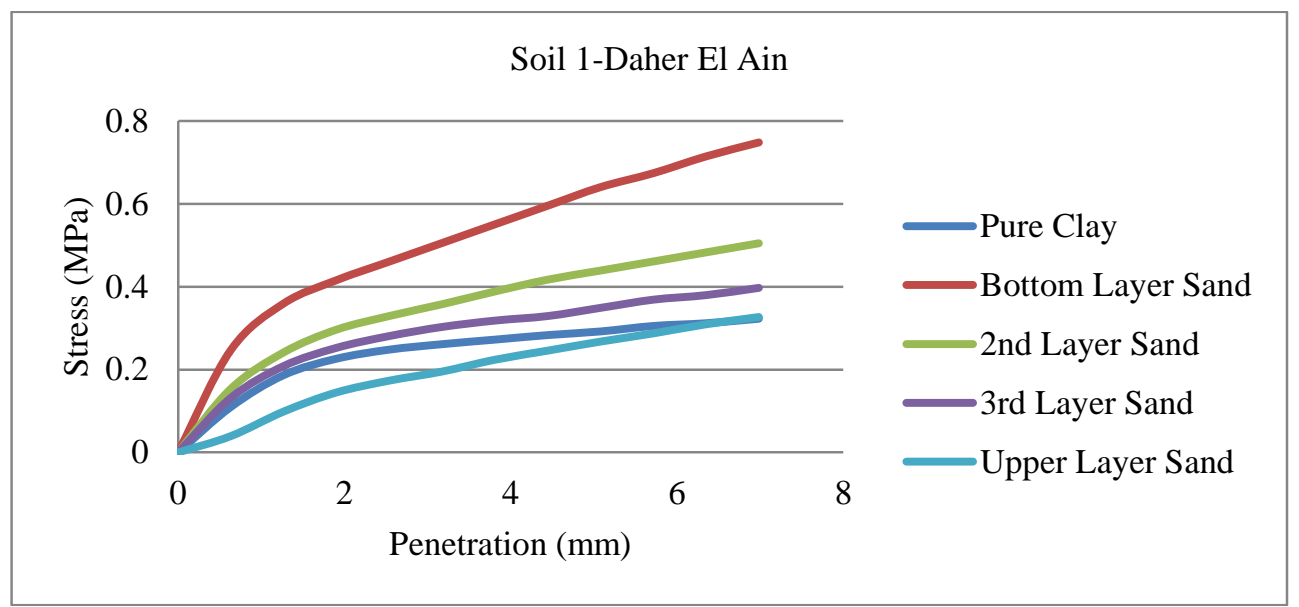

Fig. 2: Stress versus penetration of the five cases on soil 1.

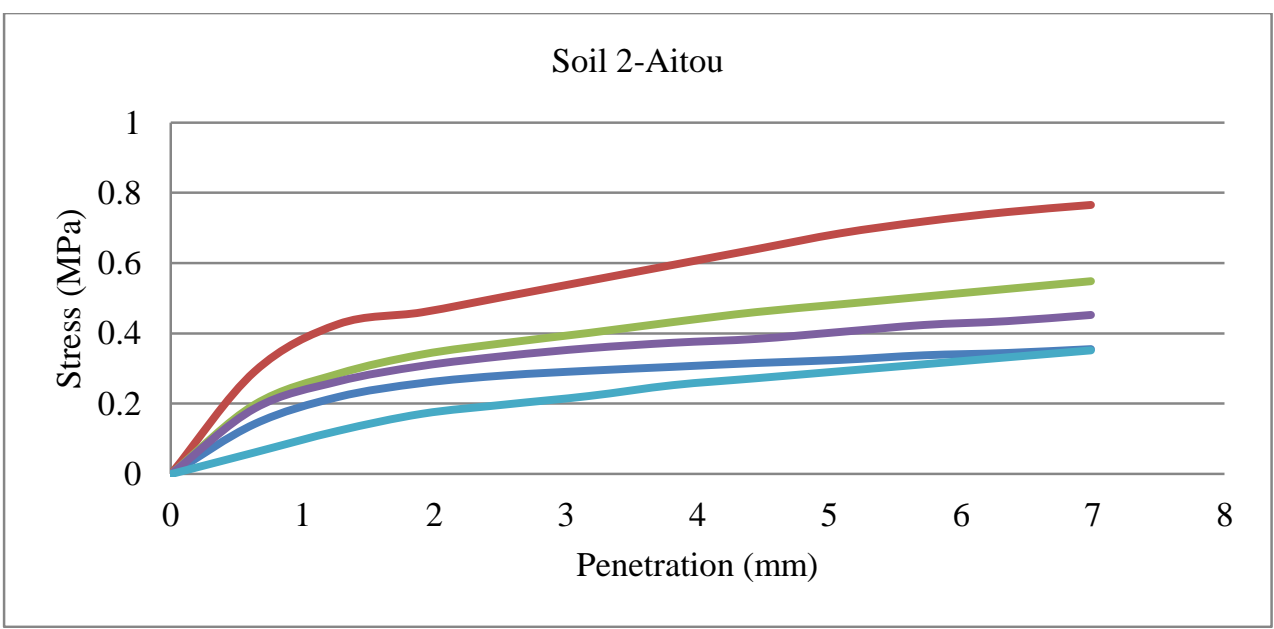

Fig. 3: Stress versus penetration of the five cases on soil 2. 


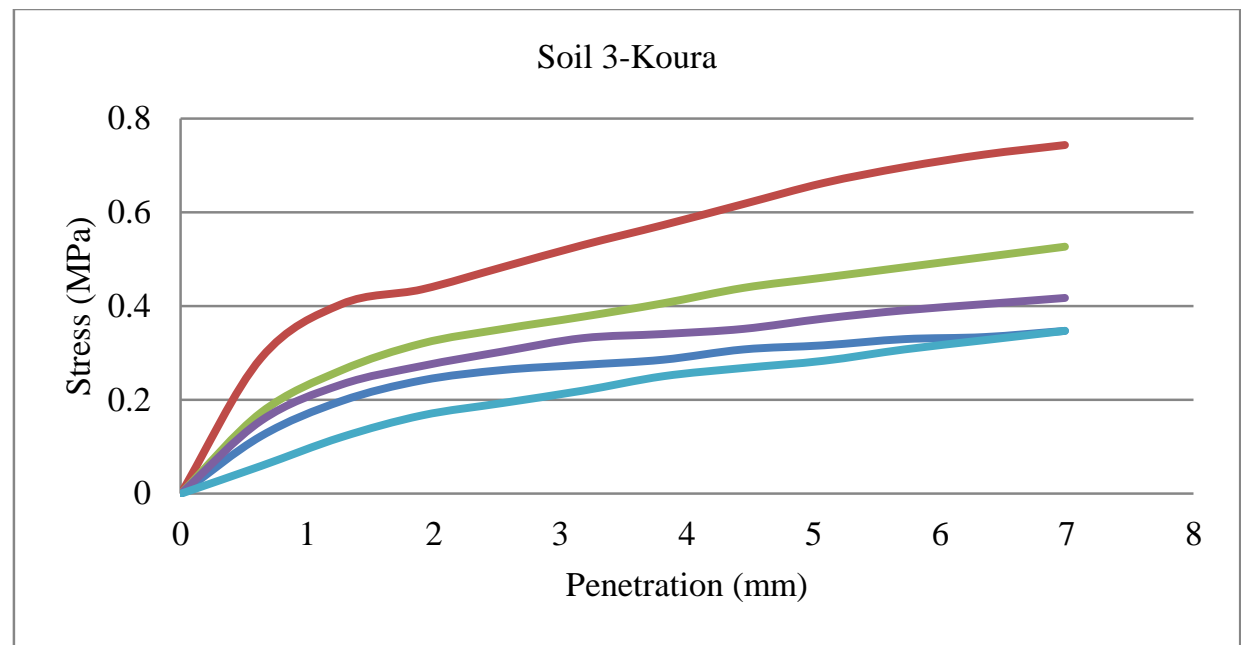

Fig. 4: Stress versus penetration of the five cases on soil 3.

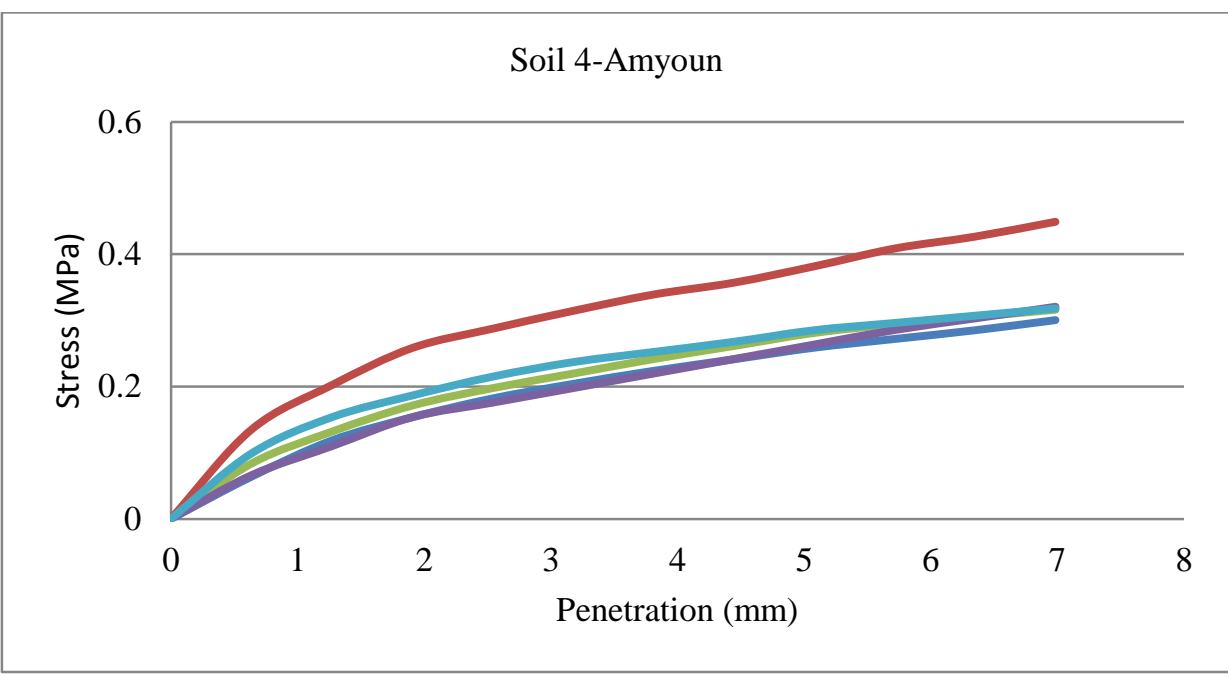

Fig. 5: Stress versus penetration of the five cases on soil 4.

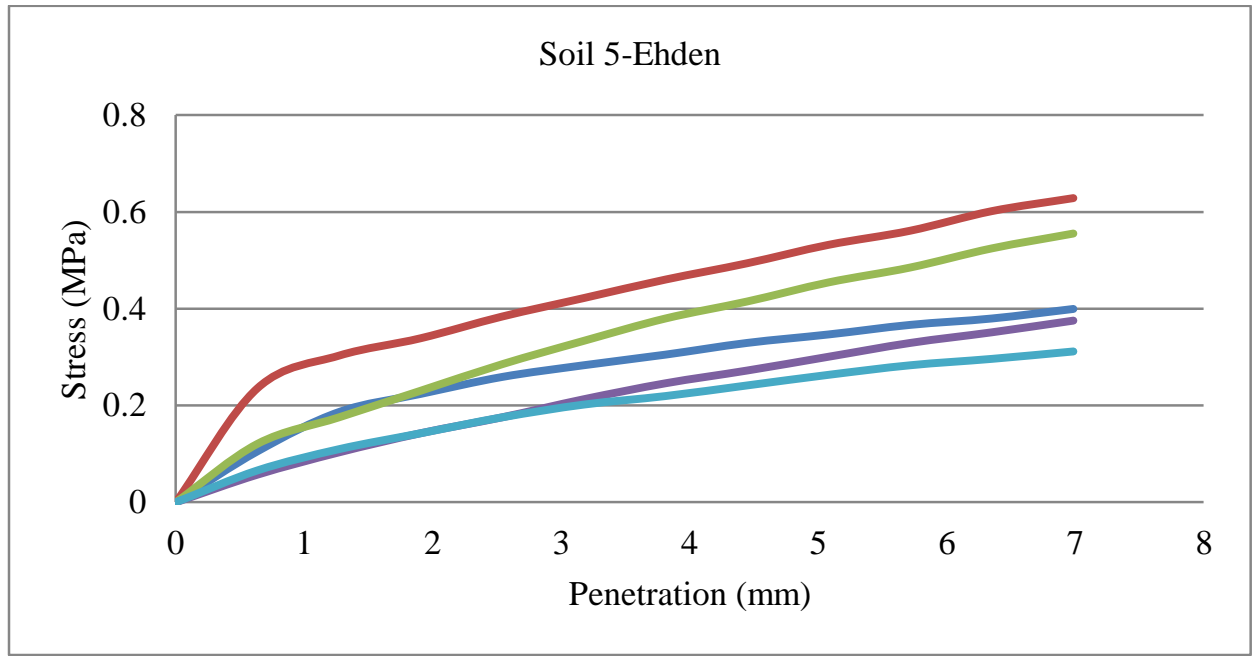

Fig. 6: Stress versus penetration of the five cases on soil 5. 


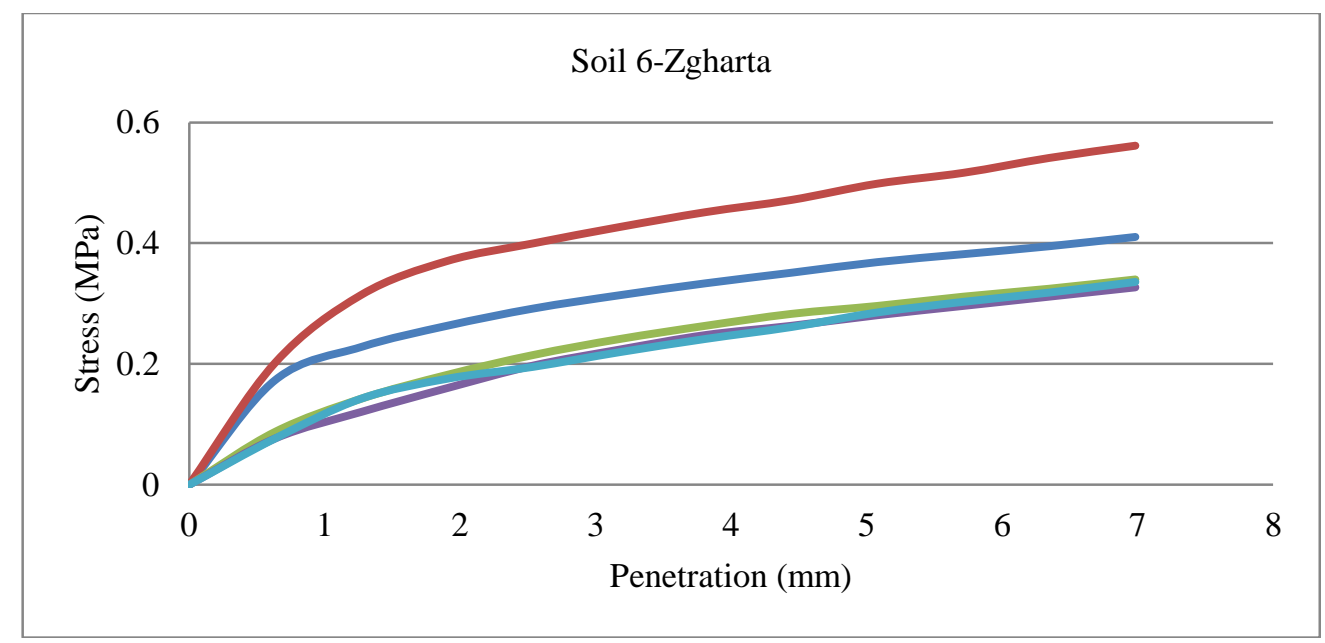

Fig. 7: Stress versus penetration of the five cases on soil 6.

After analyzing all the above curves, we can give the following results:

1- The case of the bottom sandy layer gives the higher CBR values at 0.2 inch $(5 \mathrm{~mm})$ for all the soils. The CBR increasing ratio between the pure clay and the case of the clay with bottom layer of sand are respectively: 2.21 , 2.16, 2.06, 1.46, 1.51 and 1.35. This CBR increasing is explained by the fact that the stress applied on soil at 0.2 inches penetration causes high excess of pore water pressure in clay. This excess of water pressure trapped in clay due to applied pressure will be easily dissipated by the sandy layer under higher pressure, this means under larger penetration. Having a sandy layer at bottom will help dissipating the clay water from all the layers above it due to gravity and excess of water pressure. Water will be squeezed out of clay through sandy layer. Draining water out from clay increases clay stiffness. The efficiency of filtering function of sand is at its maximum. When the sandy layer is located at middle of the mold, it plays a drainage line for only the upper clayey layers.

2- Nothing changed concerning the increasing ratio of CBR when the thickness of the sandy bottom layer was increased. This is easily explained by the fact that the filter criteria of sand govern its stiffness criteria, so whatever will be the sandy layer thickness, the increasing ratio of CBR will remains almost constant. In order to generalize this idea, further experiments should be done.

3- By changing the position of the sandy layer and getting it up, the stiffness criteria of sand governs its filter criteria. This means that when the sandy layer is moved up to reach the upper layer, its low stiffness contributes to reduction of clay CBR before the excess of clay water starts to drain out through it. It is known that sand stiffness could not be relatively increased by compacting it.

4- In the above charts, all the curves interfere at the beginning of penetration. This is explained by the fact that under low applied pressure, the drainage function of sandy layer is not activated due to the low triggered clay water pressure. While the applied pressure gets high, the sand drainage function starts working. In fact, the efficiency of the sandy layer is very clear in the case of bottom sandy layer.

5- The CBR increasing ratio in the case of bottom sandy layer is noticeable in soil 1, 2, 3 and 4, while in soil 5 and 6 this ratio relatively decreases. Soil 5 and soil 6 include granular fraction more than the other soils. That is why the sand drainage efficiency decreases for these soils because it is less efficient with types of clay having relatively higher permeability.

\section{Conclusion}

All the previous tests and their results demonstrated that the existence of sandy layer is beneficial for CBR value of clayey soil. Deeper is the sandy layer in the Proctor mold, higher is the drainage of clay excess pore water and therefore obtaining larger CBR. When the position of the sandy layer is moving up close to the ground surface, its relatively weak stiffness will affect negatively the clay CBR. 
Also this paper found that under higher pressure, the efficiency of sandy layer is larger than under lower pressure. Moreover we found that it is not important the stiffness and the thickness of the filter sandy layer, what is important are the position and the drainage capacity of sandy layer.

\section{References}

[1] P. Singh and K.S. Gill, "CBR improvement of clayey soil with Geo-grid reinforcement," International Journal of Emerging Technology and Advanced Engineering, vol. 2, no. 6, pp. 456-462, 2012.

[2] B. Soundara and K. P. Senthil Kumar, "The effect of fibres on properties of clay," International Journal of Engineering and Applied Sciences, vol. 2, no. 5, pp. 110-116, 2015.

[3] "ASTM Standard D698, Standard Test Methods for Laboratory Compaction Characteristics of Soil Using Standard Effort" in Annual book of ASTM Standards, ASTM International, 2001, pp. 78-88.

[4] "ASTM Standard D1883, Standard Test Methods for CBR of Laboratory-Compacted Soils" in Annual book of ASTM Standards, ASTM International, 2001, pp. 170-177.

[5] "ASTM Standard D422, Standard Test Methods for Particle-Size Analysis of Soils" in Annual book of ASTM Standards, ASTM International, 2001, pp. 10-17.

[6] “ASTM Standard D854, Standard Test Methods for Specific Gravity of Soil Solids by Water Pycnometer” in Annual book of ASTM Standards, ASTM International, 2001, pp. 93-99.

[7] "ASTM Standard D4318, Standard Test Methods for Liquid Limit, Plastic Limit and Plasticity Index of Soils" in Annual book of ASTM Standards, ASTM International, 2001, pp. 561-574.

[8] "ASTM Standard D1140, Standard Test Methods for Amount of Material in Soils Finer than the No. 200 Sieve" in Annual book of ASTM Standards, ASTM International, 2001, pp. 100-103.

[9] V. Olphen, "Clay-water relationship-Theory and application, A review," in Proceedings of IUPAC-Conference on Colloid and Surface Science, Budapest, 1975, pp. 46-53.

[10] S. A. Naeini and A. R. Ziaie_Moayed, "Effect of Plasticity Index and reinforcement on the CBR value of soft clay," International Journal of Civil Engineering, vol. 7, no. 2, pp. 124-130, 2009. 